\title{
Flexible prey handling, preference and a novel capture technique in invasive, sub-adult Chinese mitten crabs
}

\author{
Christopher D. Mills • Paul F. Clark • \\ David Morritt
}

Received: 3 September 2015/Revised: 26 January 2016/Accepted: 6 February 2016/Published online: 7 March 2016

(C) The Author(s) 2016. This article is published with open access at Springerlink.com

\begin{abstract}
Eriocheir sinensis (Crustacea: Brachyura: Varunidae) is one of only two crabs on the world's list of 100 most invasive aquatic invertebrates. This crab has successfully invaded NE Europe as well as the United States, eastern Canada, southern Iraq and Tokyo Bay, Japan. In England, the River Thames population of E. sinensis continues to increase in numbers and disperse westward upstream, although little is known about foraging. The present study undertook a preference and prey handling study of sub-adult mitten crabs collected from the Thames. A digital camcorder, capable of detecting infrared light, was used in the laboratory overnight to identify crab food preference, document prey handling times and record behaviour. The test prey species, namely the
\end{abstract}

Handling editor: Katya E. Kovalenko

Electronic supplementary material The online version of this article (doi:10.1007/s10750-016-2700-3) contains supplementary material, which is available to authorized users.

C. D. Mills · D. Morritt

School of Biological Sciences, Royal Holloway

University of London, Egham, UK

e-mail: Christopher.Mills.2010@live.rhul.ac.uk

D. Morritt

e-mail: d.morritt@rhul.ac.uk

P. F. Clark $(\bowtie)$

Department of Life Sciences, Natural History Museum,

Cromwell Road, London, UK

e-mail: p.clark@nhm.ac.uk amphipod Gammarus zaddachi, and two species of gastropod molluscs, Theodoxus fluviatilis and Radix peregra, were collected in the same habitat as the crabs, and all were consumed under laboratory conditions. Eriocheir were able to capture mobile $G$. zaddachi using a novel prey capture technique not previously described in brachyurans and use different skills for handling each prey species. This flexibility in prey handling may be an important contributory factor in their freshwater invasive capacity. Results indicated that the crabs had a preference for G. zaddachi which were consumed most frequently and preferentially over both mollusc species. Prey choice may be based on maximising net energy gain as consuming $G$. zaddachi was shown to provide the highest rate of potential energy consumption by the crab due, in part, to a much shorter handling time than for both species of snails.

Keywords Eriocheir sinensis · Predation · Prey handling - Gammarus zaddachi . Theodoxus fluviatilis $\cdot$ Radix peregra $\cdot$ Video recording

\section{Introduction}

Invasive species can have considerable effects on their colonised habitats such as displacing native species (Dick et al., 1995; Kiesecker et al., 2001; Sanders et al., 2003), habitat modification (Cuddington \& 
Hastings, 2004) and hybridising with native species (Daehler \& Strong, 1997). Non-native decapod crustaceans are highly prevalent in all types of aquatic habitats and, in Europe, invasive species make up $46 \%$ of all Decapoda within freshwater habitats (Ranasinghe et al., 2005; Galil, 2008; Karatayev et al., 2009). Due to their prevalence, they have a wide range of effects within their invaded habitats. These include competition for resources, e.g. Hemigrapsus sanguineus (de Haan, 1853) being able to displace juvenile Carcinus maenas (Linnaeus, 1758) from shelter (Landschoff et al., 2013) and as vectors for disease, e.g. Pacifastacus leniusculus (Dana, 1852) a known carrier of crayfish plague which has caused rapid decline in populations of Austropotamobius pallipes (Lereboullet, 1858) within the UK (Lilley et al., 1997).

One important effect invasive species can have is on trophic interactions since these are key in determining the structure of ecosystems. To determine the potential impacts, different aspects of trophic interactions can be used such as preference, feeding frequency and mutual predation. Invasive species can have vastly different trophic impacts in invaded habitats when compared to their native range. Invasive species can have an impact on prey at twice the intensity than that of native predators (Salo et al., 2007). Following this, they can have the potential to extirpate or severely reduce the population size of prey species such as the brown tree snake causing large declines in avifauna in Guam (Wiles et al., 2003). There are a number of examples where invasive decapod crustaceans have impacted trophic relationships in their invaded habitat. For example, Procambarus clarkii (Girard, 1852) has become a common prey item for several native predators in the Mediterranean (Geiger et al., 2005), whereas in Japan, the invasive $P$. leniusculus consumes a potential competitor, the native Cambaroides japonicus (de Haan, 1841), which could contribute to species replacement (Nakata \& Goshima, 2006). Other trophic effects of invasive decapods have also been observed in $C$. maenas. Predation by this species in non-native regions can induce shell thickening in populations of mussels (Freeman \& Byers, 2006) and reduce the presence of juvenile cockles (Walton et al., 2002), and the species is also capable of displacing native species from their prey (McDonald et al., 2001; Rossong et al., 2006). Understanding flexibility in feeding behaviour and feeding preferences could be useful for assessing the potential impacts that they can have on their new habitat. Predators do not consume prey following their distribution or density but usually show preference for certain prey items over others (Jackson \& Underwood, 2007; Grason \& Miner, 2012). Preference can be defined as an individual choosing to eat its most favoured prey item before others, and, as such, the last prey item eaten would be the least desired. When there is no preference, selection of prey would be random.

An invasive decapod which has spread globally is the Chinese mitten crab, Eriocheir sinensis H. Milne Edwards, 1853. This species is native to China and Korea and is listed as one of only two brachyuran crab species in the top 100 most invasive species (Lowe et al., 2000) based on their serious impact on biological diversity and/or human activities. Unlike native crab species in the UK, it spends most of its lifespan in freshwater and has a catadromous life history. This species has been present within the UK since 1935, introduced either through ballast water or intentional introduction, and had become well established by 1973 (Herborg et al., 2005). Subsequently $E$. sinensis numbers have increased greatly within the Thames (Clark et al., 1998; Gilbey et al., 2008).

Considering its global distribution, little is known about the feeding strategy of mitten crabs in invaded habitats other than being described as opportunistic omnivores, based on two analyses of gut contents using morphological evidence and stable isotopes (Rudnick \& Resh, 2005; Czerniejewski et al., 2010). In both of these studies, chironomids were shown to be the most prevalent invertebrate in their diet, although much of what was in the gut was morphologically unidentifiable, a common problem when examining the diet of decapod crustaceans due to the effectiveness of the gastric mill. The evidence for this species of crab to utilise other potential prey species is limited, although recent work has demonstrated consumption of fish eggs in laboratory conditions (Webster et al., 2015). Despite the lack of prey preference studies for E. sinensis, such data are available for other species of decapod crustaceans using a variety of different methods (e.g. Ashton, 2002; Buck et al., 2003; Jackson \& Underwood, 2007; Erickson et al., 2008; Grason \& Miner, 2012; Haddaway et al., 2012; Laitano et al., 2013). In the present study, methods devised by Taplin (2007) were used, and observations on handling times of the different prey species were also made. Handling 
time observations have been undertaken on several species of decapod crustaceans (e.g. Elner \& Hughes, 1978; Hughes \& Seed, 1981; ap Rheinallt, 1986; Hudson \& Wigham, 2003) feeding primarily on bivalves.

Sub-adult E. sinensis $(10-40 \mathrm{~mm})$ collected from the River Thames were used to establish prey preference for the most abundant species found at the same locations as the mitten crabs. As sub-adult E. sinensis are captured upstream in great numbers, they have a great potential to cause disruption to native habitat and hence the use of this size range in the current study. The main hypothesis is that there will be a difference in preference between different potential prey species, and it is predicted that sub-adult crabs will exhibit a preference for prey which are more profitable as defined by the rate of energy acquisition by the crab. Handling times were also observed and further detailed observations allow for description of the handling methods used for different prey species.

\section{Materials and methods}

Study organisms

Sub-adult crabs were collected during low spring tides at Chelsea Bridge $\left(51.4847^{\circ} \mathrm{N}, 0.1500^{\circ} \mathrm{W}\right) 22$ October 2013 and Kew Bridge $\left(51.4869^{\circ} \mathrm{N}, 0.2875^{\circ} \mathrm{W}\right)$, England, at low spring tide 31 March 2014. A total of 33 and 22 crabs were collected from each site, respectively. Another 54 crabs were also made available from previous collections made in Summer, 2013, and also from Chelsea Bridge and Kew Bridge. All crabs were housed in groups in large tanks of aerated, dechlorinated tap water within the aquarium and fed regularly with defrosted fish (perch, Perca fluviatilis) up until use in experiments.

Potential prey species were also collected at low tide on the foreshore in the vicinity of Chelsea Bridge. Three of the most abundant species were the amphipod Gammarus zaddachi Sexton, 1912 and two species of molluscs, the river nerite, Theodoxus fluviatilis (Linnaeus, 1758), and the wandering snail, Radix peregra (O.F. Müller, 1774). All are native to the UK and were selected as they represent different morphologies and habits and thus different challenges when it comes to prey handling. The amphipod, G. zaddachi, is a fastswimming species; T. fluviatilis is an operculate gastropod with a non-spiral shell which is usually closely attached to the substrate; $R$. peregra lacks an operculum and has a spiral shell. Preliminary experiments, in which aquaria were set up with individual mitten crabs with four specimens of each potential prey species and left for 7 days, showed that all three species were consumed.

\section{Preference experiments}

To determine the preference of crabs for the three prey species, trials were completed using the method described by Taplin (2007). This method assumes that an individual consumes prey in the order of preference. Therefore, each prey item is assigned a rank depending on order of consumption, i.e. the first prey eaten will be assigned rank 1 , the second prey 2 and so on until all prey have been assigned a rank. When a prey item is not consumed, it is considered last, or if there are multiple prey left unconsumed, they are considered tied for last and given an average rank. In this way, unconsumed prey items are considered as the predator having the least preference for them (Taplin, 2007). The total number of prey items consumed in each trial was recorded.

Fifty crabs were starved for 7 days prior to the preference trials to assure maximum prey consumption. Furthermore, only crabs which had both chelae present were used so they would be feeding at optimum efficiency. Each crab was only trialled once. The prey species used for these trials were $G$. zaddachi, $T$. fluviatilis and $R$. peregra.

During preference trials, crabs were placed individually in each aquarium and given $6 \mathrm{~h}$ to acclimate. After acclimation two of each prey species ranging from 7 to $10 \mathrm{~mm}$ in length (six prey items in total) were placed randomly in the aquaria to help reduce any initial bias towards nearby prey. Crabs were then left for a period of $16 \mathrm{~h}$ over night with the prey, 3-h light followed by $12 \mathrm{~h}$ dark and then one more hour of light to record the predominantly nocturnal feeding activity. During this period, three aquaria were recorded simultaneously from underneath by being positioned on top a glass panel supported by a frame.

A JVC HZ-300 digital camcorder converted to full spectrum detection and set to time lapse, capturing frames at 1-s intervals, was used to record feeding behaviour. All recorded footage was slowed down using MPC-HC 1.7.6 software during review. The 
camcorder was equipped with two darkness activated infrared emitters directed at the aquaria so recording could be captured in darkness. After the trial, the crabs were removed, the aquaria were cleaned, and the water was replaced for the next trial. Footage was reviewed taking note of the order in which prey were consumed. Gender, carapace width and chela height were noted as $0.1 \mathrm{~mm}$ using a dial calliper after the trial so not to cause any unnecessary stress prior to trials. Controls with six prey items and no crab showed no natural mortality in prey species over the same period of time.

All feeding experiments were undertaken in clear aquaria measuring $255 \mathrm{~mm} \times 150 \mathrm{~mm} \times 190 \mathrm{~mm}$ $(L \times W \times D)$. These were filled with $1500 \mathrm{ml}$ of dechlorinated tap water and were aerated with an air stone attached to an air pump. The aquaria were set up within the marine aquarium at RHUL with a constant temperature of $11 \pm 1^{\circ} \mathrm{C}$ and a L:D 12:12 cycle using fluorescent lighting.

\section{Prey handling}

In a separate series of experiments, twenty mitten crabs were fed G. zaddachi, ten T. fluviatilis and $11 R$. peregra in the preference trials. Some crabs were used for multiple species due to the limited availability. Despite this, each crab was only used once for each prey species.

The crabs were offered a prey species within the same $7-10 \mathrm{~mm}$ size range as used above. For $G$. zaddachi two individuals were offered to the crabs because this increased the likelihood of capture to allow behavioural observations. For both mollusc species, individuals were placed directly in front of the crabs. If a crab did not consume any prey item, no data were collected, and it was removed from the aquarium and replaced with another specimen. Crabs were recorded whilst feeding to allow description of handling methods and to provide accurate handling times.

Handling time was defined as the period starting from when the crab captured the prey until the point at which the crab was no longer interacting with it. As the morphology of G. zaddachi and the two snail species differs, the end point of handling time was defined differently. For G. zaddachi, the end of handling time was defined as the point at which the entire prey item was consumed and for the two snail species as the point at which the crab abandoned the empty shell for a period of $1 \mathrm{~min}$; this time was subtracted from the total handling time.

The total handling time for the two snail species was also divided into several periods. In the case of $T$. fluviatilis, it was divided into three periods as follows: time to remove operculum, time to remove the flesh and time spent picking at the empty shell. The first period started once the crab picked up the shell with its chelae and finished when it had completely removed the operculum from the foot of the snail. The next period started once the operculum had been detached and continued until the flesh was removed from the shell and had finished consuming the flesh. The final period started once the flesh had been consumed and the crab began to pick at the shell with its chelae. This period finished once the crab had dropped the shell and left it for $1 \mathrm{~min}$. For $R$. peregra, handling was divided into two periods: the first started once the crab picked up the shell and ended once all flesh had been consumed. The final period was the same as $T$. fluviatilis: it started once the flesh had been removed and finished once the crab had abandoned the shell for $1 \mathrm{~min}$.

To determine the rate of energy consumption during prey manipulation, the handling time was combined with the energy content for each prey species which was gathered from relevant literature. This was calculated by converting the length of the prey item used in the sample to wet weight using a regression equation for each prey species (Electronic Supplementary Material 1); wet weight was changed to shell-free dry weight using relevant conversion factors from Rumohr et al. (1987). This was then combined with the handling time of each sample and the average energy content of the relevant species (or related species) to provide the rate of energy consumption for the crab during manipulation and ingestion.

\section{Statistical analysis}

All statistical analyses were completed using SPSS software. Data were checked for normality and homogeneity of variance using Shapiro-Wilk and Levene's test, respectively. As data for prey preference scores, average handling times and energy acquisition rates did not meet the assumptions for parametric tests, Kruskal-Wallis tests followed by post hoc Mann-Whitney $U$ tests were used to 
determine differences between treatments. Linear regression analysis was used to explore the relationships between size of crabs and handling times for the different prey species.

\section{Results}

Preference

During preference trials $G$. zaddachi was the most frequently consumed species, with both mollusc species being consumed far less frequently during the experimental period (Table 1). At least one $G$. zaddachi was eaten in every trial and both specimens were eaten in $80 \%$ of studies. Snails were eaten far less frequently, with one T. fluviatilis consumed in $40 \%$ of trials and one $R$. peregra in $18 \%$. Occasions where the crabs consumed both the $T$. fluviatilis happened more frequently than instances where a single $R$. peregra was consumed (e.g. $20 \%$ of trials). There was a significant difference in preference for different prey species $\left(\chi^{2}=107.554, P<0.001\right)$. It was found that crabs have the strongest preference for $G$. zaddachi over T. fluviatilis $(U=14, Z=-8.74, P<0.001)$ and $R$. peregra $(U=1.5, Z=-8.81, P<0.001)$ with a preference score of 1.9. Between the two snails, there was a smaller preference for $T$. fluviatilis over $R$. peregra $(U=782, Z=-3.43, P=0.001)$ with preference scores of 4.1 and 4.5, respectively (Fig. 1). It was also shown that male crabs that have a preference for $T$. fluviatilis over $R$. peregra $(U=113, P<0.001)$, whereas for female crabs, there was no preference between the two mollusc species (Fig. 2).

Table 1 Percentage of occasions during preference trials where one or both of each prey were consumed

\begin{tabular}{lc}
\hline Prey consumed & $\begin{array}{l}\text { Percentage of } \\
\text { occurrence }\end{array}$ \\
\hline G. zaddachi & 100 \\
T. fluviatilis & 40 \\
$R$. peregra & 18 \\
Both G. zaddachi & 80 \\
Both $T$. fluviatilis & 20 \\
Both $R$. peregra & 6 \\
\hline
\end{tabular}

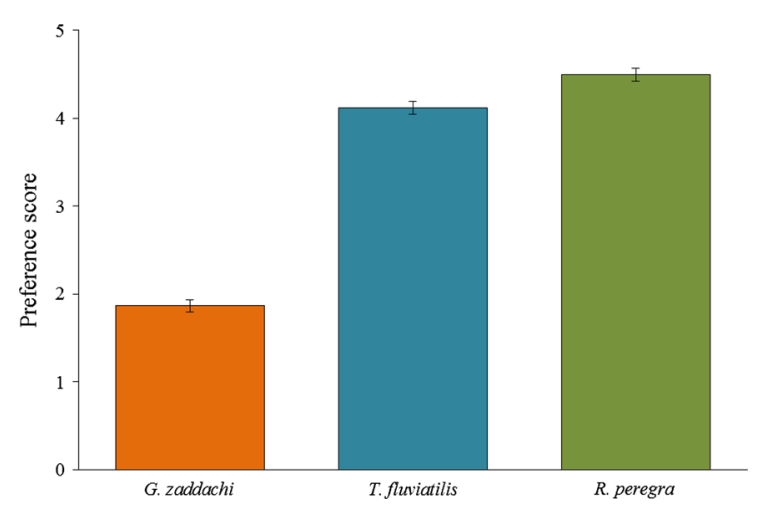

Fig. 1 Average preference score \pm SE for three prey species in sub-adult Eriocheir sinensis

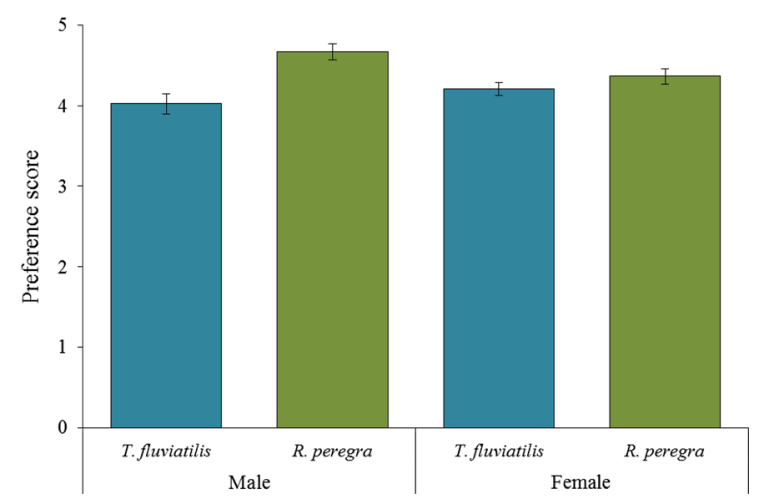

Fig. 2 Average preference score \pm SE for male and female Eriocheir sinensis preying on $T$. fluviatilis and $R$. peregra

\section{Handling methods}

Mitten crabs displayed three different methods of prey capture for the amphipod G. zaddachi. For two capture methods (see Electronic Supplementary Material 2 for examples), the crab exhibited minimal movement or remained stationary. In the first method, it stayed in this position until the prey swam underneath its sternum and between the merus and the propodus of the chela. At this point, the propodus was snapped shut against the merus trapping the amphipod. The amphipod was effectively speared between a row of spines on the inner surface on the propodus (see Fig. 3) and held firmly against a row of spines on the inner margin of the merus (see Fig. 4). This adaptation potentially allows capture of smaller, faster moving prey items than if using the pincers alone which almost certainly involves a finer degree of motor control of the dactyl and propodus. Indeed, this could be said of 


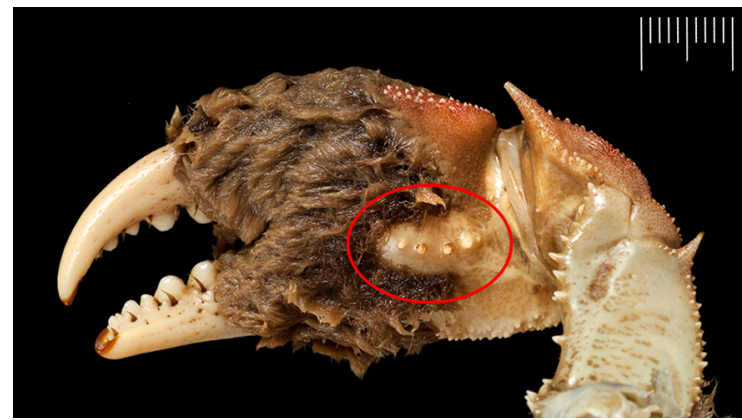

Fig. 3 Eriocheir sinensis H. Milne Edwards, 1853; NHM 1993:1, River Cray, Hall Place near Crayford, Kent, collected B. Martin, 20 August 1992, right chela showing spines on internal surface of propodus (circled). These spines are normally obscured by the mittens in male crabs. Taken by Harry Taylor, NHM Photo Unit. Scale bar in mm divisions of $1 \mathrm{~cm}$

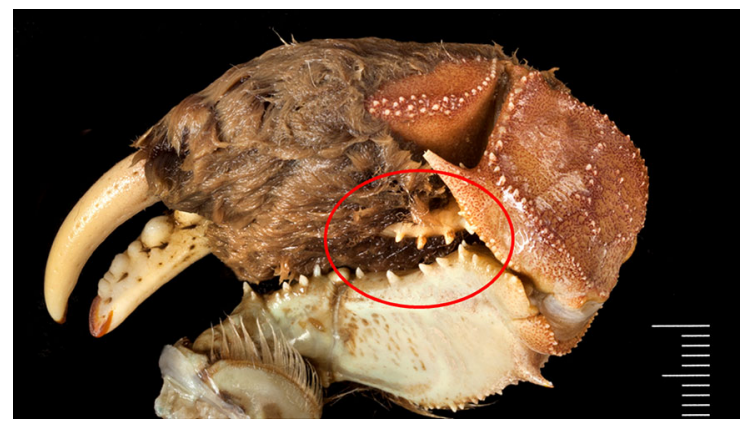

Fig. 4 Eriocheir sinensis H. Milne Edwards, 1853; NHM 1993:1, River Cray, Hall Place near Crayford, Kent, collected B. Martin, 20 August 1992, showing the prey grasping coadaptation between spines on internal surface of the right chela propodus and those on the merus (circled). These spines are normally obscured by the mittens in male crabs. Taken be Harry Taylor, NHM Photo Unit. Scale bars in $\mathrm{mm}$ divisions of $1 \mathrm{~cm}$

all three methods used when capturing amphipods. The head of the amphipod was then sometimes crushed by the pincers (propodus and dactylus) of the other chela. For the second method, the crabs would also stay in a stationary position until the prey swam underneath its sternum at which point the crab trapped the prey against the ventral surface of the body using the pereiopods nearest to the prey and then used its nearest chela to either trap the prey against its body using the row of spines on the merus or to grasp the prey. When the prey was securely trapped against the sternal plates, the crab then grasped the amphipod using the free chela. The pereiopods that were holding the prey in place would then release the prey. In cases where one chela was used to trap the prey against the ventral surface of the body, this chela would subsequently be manoeuvred to also hold on to the prey. In both cases once grasped with the chelae, the crab would then manipulate the prey towards the mouthparts where the third maxillipeds were used to aid in holding the prey in place. The prey was then guided through the mouthparts to the mandibles which were used to shred the prey before being passed though the mouth into the gastric mill. Once the main prey portion was consumed, the crab then picked up any soft fragments remaining and these were consumed.

The third method of capture involved the crab actively trying to catch the prey. Here the crab pounced towards the nearby prey and used its chelae to scoop and trap the prey against the ventral surface of the body similarly to previous description. The prey was then carefully manoeuvred by the chelae, these being used in turn to grip onto the prey, and, if necessary, the second pereiopods were also used to help hold the prey. From this point onwards, prey was processed as described for the first capture method.

As molluscs are slow moving, the capture of these prey items was simple, though in the case of $T$. fluviatilis it took a short period of time to remove the individual from the surface of the aquarium. The handling method for T. fluviatilis initially involved picking up the individual with the chelae. Next the crab positioned the chelae on both sides of the aperture lip with the second pereiopods used to support the shell. In this position, the crab pulled at both sides of the shell aperture using the chelae. During this process, the crab would pause occasionally to use one chela to pinch at the rear of the operculum where it is attached to columellar muscle at the dorsal end of the foot. After a period of time, the operculum was released, and, at this point, the chela was used to remove the operculum with the majority flesh. The flesh was then moved towards the mouth parts where the third and second maxillipeds were used to guide the flesh through the mouth. Once the majority of flesh was removed, the crab continued to pick at the empty shell removing any remnants of flesh inside. The crab occasionally held the shell with its third maxillipeds as well as the chelae to allow scraping of the outside of the shell with the second maxillipeds. Eventually, the crab abandoned the empty shell.

The handling method for $R$. peregra started with the crab picking up the snail with the chelae and then manipulating it into a position where it could begin 
removing the flesh from the shell. The crab then removed pieces of flesh through the aperture of the shell using one chela, whilst the other chela held on to the lip of the shell aperture. These pieces of flesh were then passed to the mouthparts where the third and second maxillipeds were used to guide it through the mouth. On occasions when all the flesh could not be removed through the aperture, the crab would begin to break the shell of the snail along the lip of the aperture using the chelae. Once sufficient shell had been detached, the crab resumed removing the flesh from the shell. When the majority of flesh had been separated, the crab continued to pick at the empty shell remains removing any remnants of flesh. During handling when small chunks of flesh were removed the flagellum-like extension of the exopod on the third and second maxillipeds were flicked constantly. Sample footage of handling methods for all three prey species can be viewed at http://tinyurl.com/kqox $89 \mathrm{j}$.

\section{Handling times}

Handling time for G. zaddachi prey was shown to be best related to crab carapace width with a significant negative linear regression $\left(R^{2}=0.381, P=0.004\right)$ compared to the relation with average chela height $\left(R^{2}=0.315, P=0.01\right.$; see Fig. 5). Handling time for T. fluviatilis prey was best related to average chela height with a significant linear regression $\left(R^{2}=0.653, P=0.005\right)$ compared to the relation with average carapace width $\left(R^{2}=0.332, P=0.081\right.$; see Fig. 6). Similarly with $R$. peregra, handling time was best related to average chela height $\left(R^{2}=0.397\right.$, $P=0.038)$ compared to the relation with carapace width $\left(R^{2}=0.274, P=0.098\right.$; see Fig. 7).

There was a significant difference in handling times between the three prey species $\left(\chi^{2}=29.663\right.$, $P<0.001)$. The handling time of $G$. zaddachi was significantly shorter $(<300 \mathrm{~s})$ than $T$. fluviatilis ( $U=0, Z=-4.40, P<0.001,>3,000 \mathrm{~s})$ and $R$. peregra $(U=6, Z=-4.29, P=0.003$, ca. $2,000 \mathrm{~s})$. It was also found that the handling time for R. peregra was significantly shorter than that of $T$. fluviatilis ( $U=26, Z=-2.04, P=0.041$; see Fig. 8).

When combining energy values of each prey species (Table 2) with handling time a difference was found between prey species $\left(\chi^{2}=30.030\right.$, $P<0.001)$. Gammarus zaddachi provided the highest rate of energy consumption being significantly higher than both $T$. fluviatilis $(U=0, \quad Z=-4.38$, $P<0.001)$ and $R$. peregra $(U=0, Z=-4.52$, $P<0.001)$. There was no difference in the calculated rate of energy consumption between the two mollusc species $(U=38, \quad Z=-0.317, \quad P=0.749 ; \quad$ see Fig. 9).

\section{Discussion}

This present study demonstrated that the amphipod Gammarus zaddachi and the molluscs T. fluviatilis and $R$. peregra are consumed by sub-adult Chinese mitten crabs under laboratory conditions. All three species are similar to prey items consumed in their SE Asian native habitat where Eriocheir feed on snails and freshwater shrimp (Hymanson et al., 1999). Out of the three native UK species consumed, mitten crabs demonstrated a clear preference for G. zaddachi and demonstrated considerable flexibility in handling strategies between different types of prey. Similar flexibility in feeding behaviour for different types of molluscan prey, linked to maximising feeding efficiency, has been demonstrated for Cancer novaezelandiae (Creswell \& McLay, 1990).

The results of this study showed that handling times for each of these prey species decreased as crab sized increased. For the handling time of G. zaddachi, it was shown crab carapace width, as an indication of mouth aperture size, provided the best fit as this was the most likely limiting factor in prey handling. This is because G. zaddachi is relatively soft-bodied and of relatively small size, so the chelae were not required beyond manipulating the prey towards the mouthparts where it is dismembered and guided into the mouth. In comparison, for the molluscs, it was shown that chela height provided a better indicator of handling time as these were used extensively in prey handling; either breaking through the operculum for T. fluviatilis or the shell for $R$. peregra. The average handling time for each prey species showed that G. zaddachi took a significantly shorter amount of time to handle compared to the two snail species. Between the two snail species handling time for T. fluviatilis was significantly longer than $R$. peregra due to two factors: the presence of an operculum and having a relatively thicker shell. This was shown during handling of $T$. fluviatilis where crabs were unable to break through the shell and had to resort to breaking through the 
Fig. 5 Handling time of $G$. zaddachi prey against A carapace width and B average chela height for E. sinensis

Fig. 6 Handling time of $T$. fluviatilis prey against A carapace width and B average chela height for E. sinensis
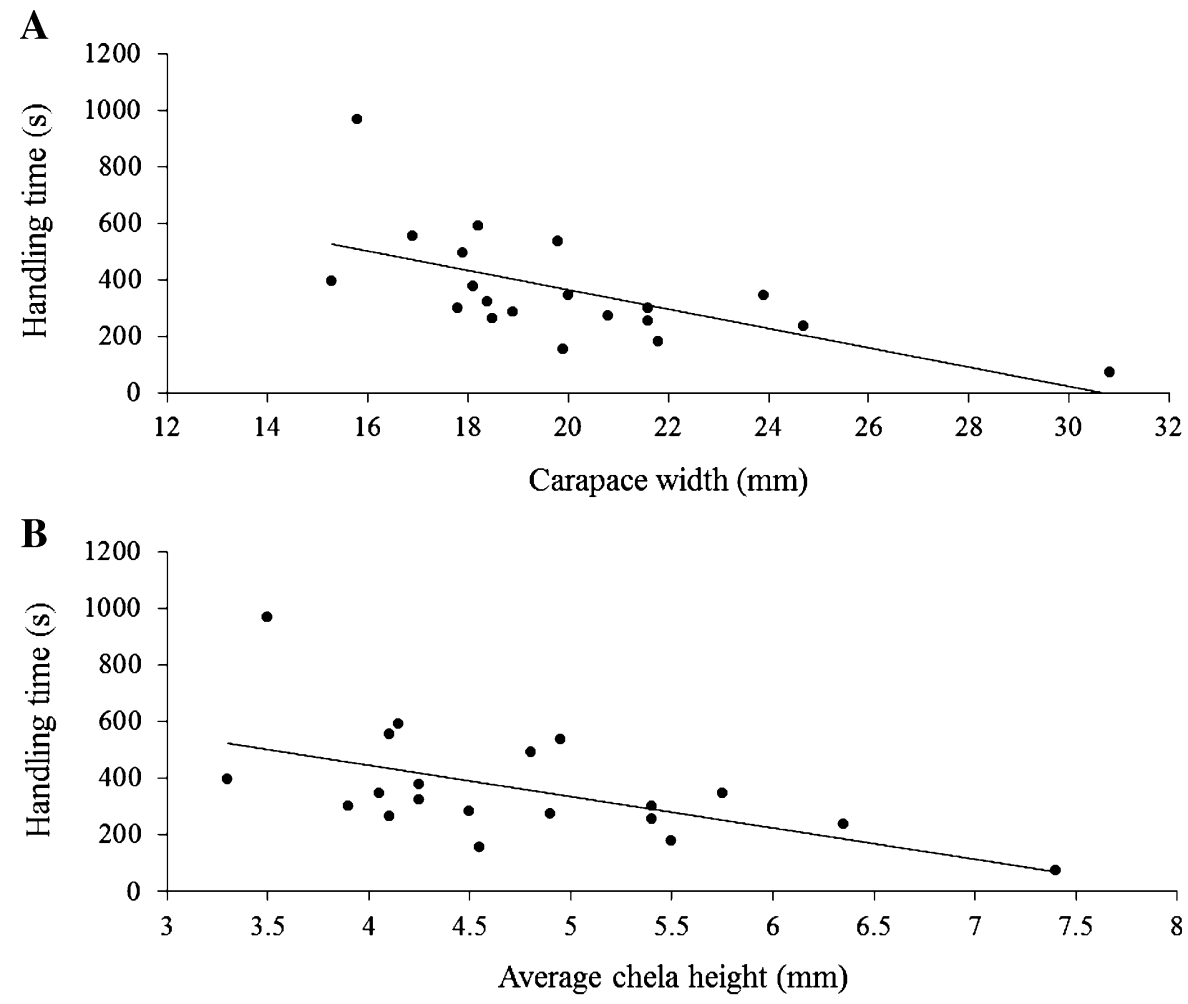

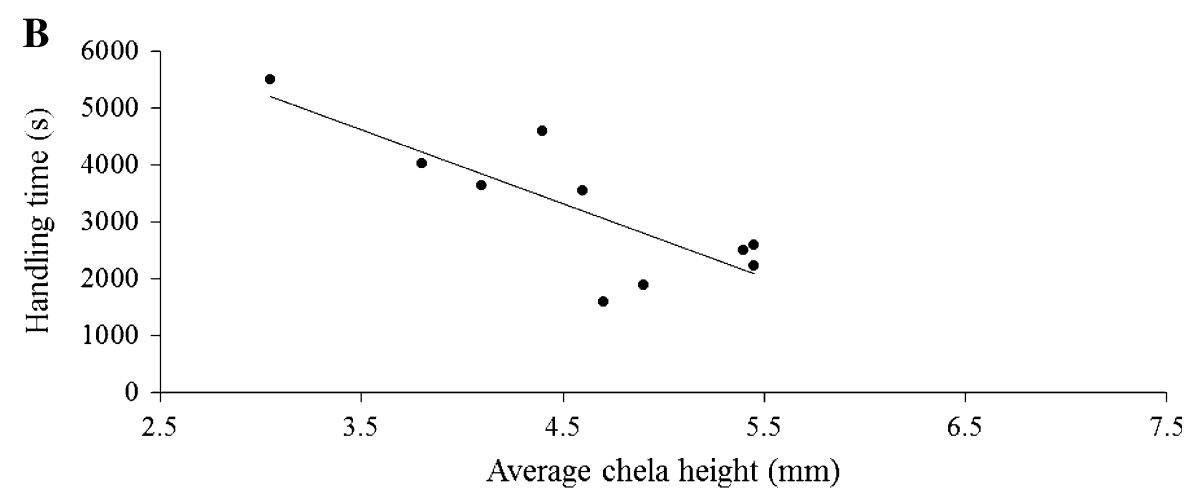


Fig. 7 Handling time of $R$. peregra prey against A carapace width and B average chela height for E. sinensis
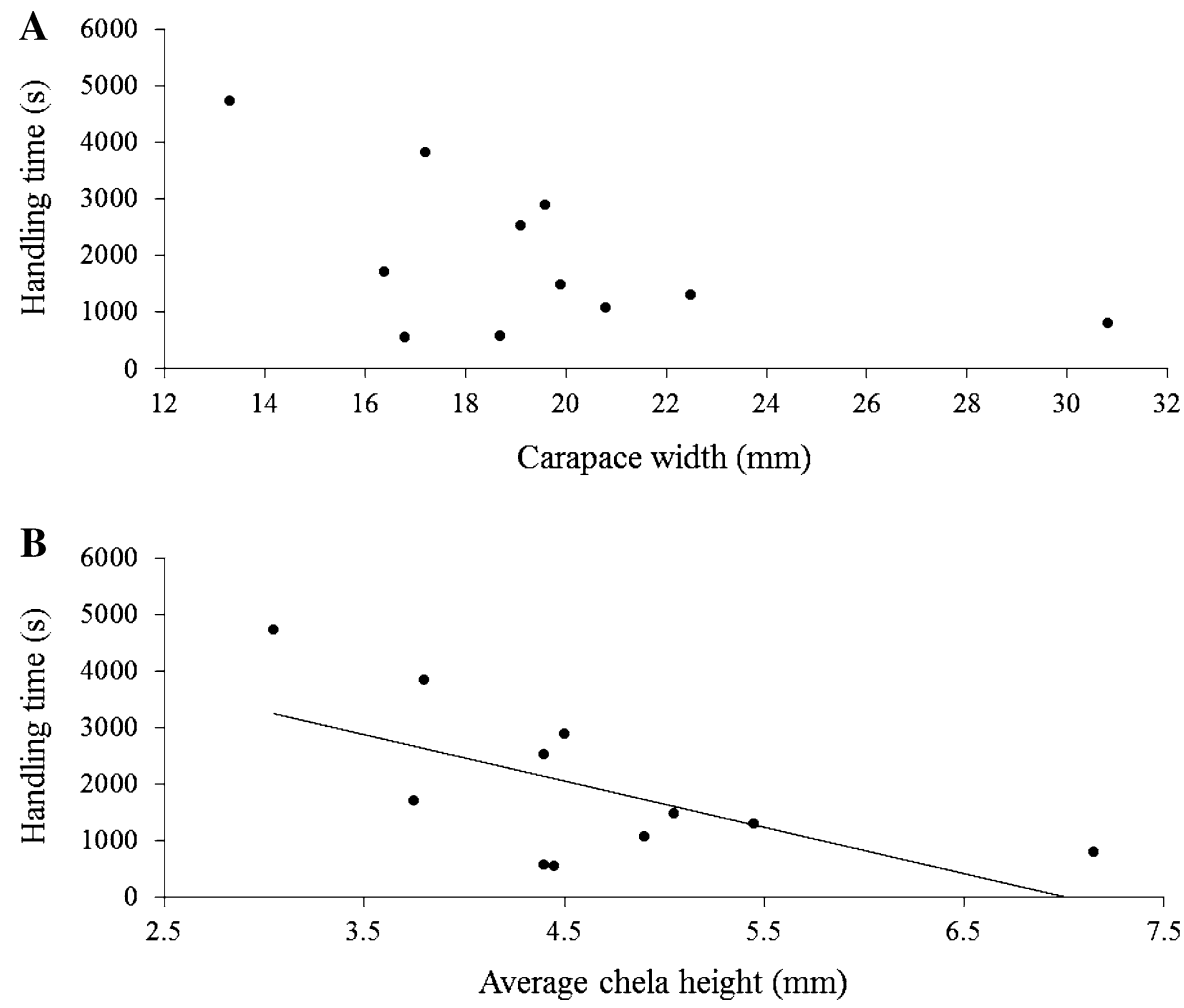

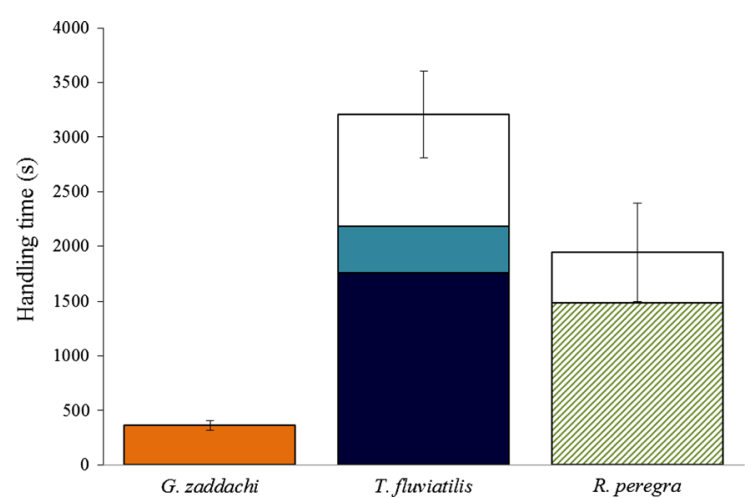

Fig. 8 Average handling time \pm SE for $G$. zaddachi $=$ total time to complete ingestion; for T. fluviatilis time to complete ingestion comprising operculum removal (dark), handling empty shell (white) and ingestion (light); and for R. peregra time to complete ingestion comprising handling empty shell (white) and ingestion/shell removal (hatched)

operculum which required more time. In comparison, whilst handling snails, other crab species primarily crush the shell rather than pull the flesh from the aperture which shortens handling time (Zipser \& Vermeji, 1978; Bertness \& Cunningham, 1981; Schindler et al., 1994; Shigemiya, 2003; Rochette et al., 2007). This behaviour of crushing a molluscan shell may not be possible in sub-adult E. sinensis as they do not possess a distinct crushing chela, and also, in the present study, the crabs were relatively small individuals (10-40 $\mathrm{mm}$ carapace width). Carcinus maenas and Callinectes sapidus Rathbun, 1896 can use a similar technique to that described for E. sinensis given $R$. peregra when handling other species of snails. Both these species use their chelae to pull the flesh directly from the species of snail given through the aperture or use their chelae to chip around the aperture to gain better access (Schindler et al., 1994; Rochette et al., 2007). Eriocheir. sinensis showed unique methods for handling T. fluviatilis compared to other species of crabs handling related species from the Family Neritidae. Ozius verreauxii Saussure, 1853 and Eriphia squamata Stimpson, 1860, whilst failing to crush the snail shell, break only the shelf of the shell allowing them to remove the operculum and then remove the flesh from the shell (Bertness \& Cunningham, 1981). Another technique is used by E. smithii MacLeay, 1838, and here the crab would break away the shell from the lip of the aperture until it could remove the flesh (Shigemiya, 2003). A possible 
Table 2 Dry weight energy content for the prey species (shell-free dry weight for snail)

\begin{tabular}{|c|c|c|}
\hline Species & Energy content $\left(\mathrm{J} \mathrm{mg}^{-1}\right)$ & Author \\
\hline G. zaddachi & 15.16 & Rumohr et al. (1987) \\
\hline T. fluviatilis $^{\mathrm{a}}$ & 20.48 & Hughes (1971) \\
\hline R. peregra & 12.33 & Lien (1978) \\
\hline
\end{tabular}

${ }^{a}$ Average energy content for Nerita sp. (data for the most closely related species available in literature)

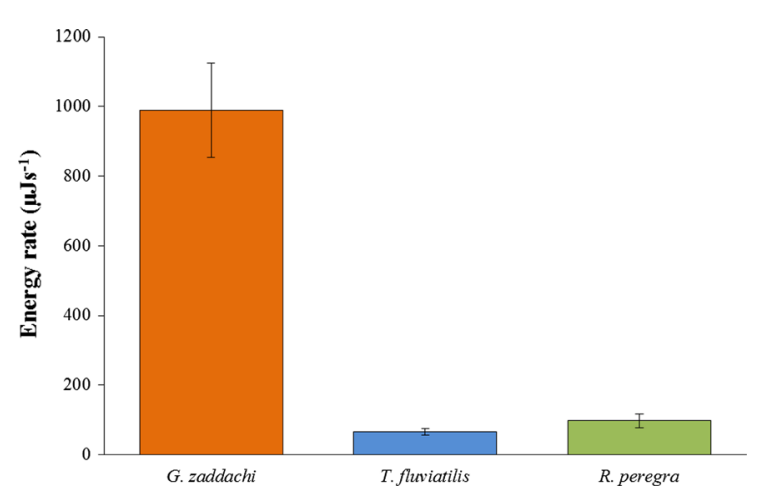

Fig. 9 Average rate of energy consumption \pm SE by sub-adult Eriocheir sinensis for three prey species

explanation for why Eriocheir. sinensis did not display any of these techniques, whilst handling $T$. fluviatilis is that the individuals used were all sub-adults and consequently were not strong enough to break the shell using their chelae.

Of the three prey species studied, mitten crabs preferred G. zaddachi which had shorter handling time and higher potential energy consumption rates. Furthermore, these preference results suggest that despite the high abundance of both snail species in the habitat, crabs have little interest in consuming them, especially $R$. peregra. It is possible that the sub-adult crabs in this study chose prey based primarily on energy maximisation similar to what is found in other species of decapods (Elner \& Hughes, 1978; Hughes \& Seed, 1981; Gherardi et al., 1989; Weissburg, 1993). For example, when given equal amounts of both optimum prey (providing the highest rate of energy acquisition) and suboptimum prey, C. maenas would preferentially consume optimum prey at a frequency of $72 \%$ (Elner $\&$ Hughes, 1978). Of the two snail species used here, the mitten crabs slightly preferred T. fluviatilis even though this involved a significantly longer handling time. A possible explanation for this is that $T$. fluviatilis could have higher energy content than $R$. peregra as the latter has a lower energy content of $12.33 \mathrm{~J} \mathrm{mg}^{-1}$ (Lien, 1978) which is below the average for three nerite species (Nerita tessellata, $N$. versicolor and N. peloronta) of $20.48 \mathrm{~J} \mathrm{mg}^{-1}$ (Hughes, 1971). However, there was no difference in the rate of energy consumption between the two species of snails despite $R$. peregra being easier to handle.

Feeding on the amphipod, G. zaddachi, involved the use of novel prey capture techniques, utilising well-developed spination on certain elements of the chelipeds (see Figs. 3, 4). To our knowledge, this is the first description of the function of this ornamentation in this group of decapods. Even though there was a high preference G. zaddachi during these laboratory trials, it is possible that this prey would be difficult for sub-adult mitten crabs to catch in the wild as they are highly mobile and are clearly not limited to the confines of an aquarium. During this study, however, the sub-adults appeared to be competent at catching G. zaddachi. Another factor that could increase the likelihood of capture in the wild is that $G$. zaddachi appeared in high numbers under rocks in exactly the same habitat where small mitten crabs were usually encountered. It is also possible that $G$. zaddachi do not recognise the crabs as a potential predator making them easier to catch, as it was noted in this study that individuals would swim under crabs often leading to their capture. This suggestion is based on findings for another invasive decapod, the signal crayfish, Pacifastacus leniusculus, where the presence of chemical cues from this species did not lower locomotory activity in gammarid prey, whereas chemical cues from fish did (Åbjörnsson et al., 2000). As the crabs are able to catch G. zaddachi, it is entirely possible they are capable of catching other highly mobile prey. There are reports that other species of crab do consume mobile amphipods (Williams, 1982; Stehlik, 1993; Buck et al., 2003; Griffen \& Byers, 2006). 
Whilst these trials were carried out under laboratory conditions, with a limited size range of crabs, the results do demonstrate that this invasive species has the capacity for considerable flexibility in its prey handling techniques. This may be linked to their considerable success in invading new habitats and exploiting new food resources (see Bentley, 2011). Furthermore, in the trials, less obvious, fast-moving, targets were preferred, and their capture utilised a previously undescribed technique and, in the process, provide an explanation for the function of cheliped spines. The present laboratory results also demonstrate the potential for this species to consume these prey types in the field and a flexibility in feeding behaviour, both of which may be of concern when considering the potential impact on native biota.

Acknowledgements We thank Seyit Ali Kamanli for help with field work and Jessica Webster for providing some crab specimens. We also thank Neil Morley for assistance provided in the laboratory. The photographs in this paper were taken by Harry Taylor, Natural History Museum Photo Unit.

Open Access This article is distributed under the terms of the Creative Commons Attribution 4.0 International License (http:// creativecommons.org/licenses/by/4.0/), which permits unrestricted use, distribution, and reproduction in any medium, provided you give appropriate credit to the original author(s) and the source, provide a link to the Creative Commons license, and indicate if changes were made.

\section{References}

Åbjörnsson, K., J. Dahl, P. Nyström \& C. Brönmark, 2000. Influence of predator and dietary chemical cues on the behaviour and shedding efficiency of Gammarus pulex. Aquatic Ecology 34: 379-387.

ap Rheinallt, T., 1986. Size selection by the crab Liocarcinus puber feeding on mussels Mytilus edulis and on shore crabs Carcinus maenas: the importance of mechanical factors. Marine Ecology Progress Series 29: 45-53.

Ashton, E. C., 2002. Mangrove sesarmid crab feeding experiments in Peninsular Malaysia. Journal of Experimental Marine Biology and Ecology 273: 97-119.

Bentley, M. G., 2011. The global spread of the Chinese mitten crab Eriocheir sinensis. In: Galil, B. S., P. F. Clark \& J. D. Carlton (eds), The Wrong Place - Alien Marine Crustaceans: Distribution, Biology and Impacts, Invading Nature. Springer Series in Invasion Ecology 6. Springer, Dordrecht: 107-128.

Bertness, M. D. \& C. Cunningham, 1981. Crab shell-crushing predation and gastropod architectural defence. Journal of Experimental Marine Biology and Ecology 50: 213-230.

Buck, T. L., G. L. Breed, S. C. Pennings, M. E. Chase, M. Zimmer \& T. H. Carefoot, 2003. Diet choice in an omnivorous salt-marsh crab: different food types, body size, and habitat complexity. Journal of Experimental Marine Biology and Ecology 292: 103-116.

Clark, P. F., P. S. Rainbow, R. S. Robbins, B. Smith, W. E. Yeoman, M. Thomas \& G. Dobson, 1998. The alien Chinese mitten crab Eriocheir sinensis (Crustacea: Decapoda: Brachyura) in the Thames Catchment. Journal of the Marine Biological Society of the United Kingdom 78: 1215-1221.

Creswell, P. D. \& C. L. McLay, 1990. Handling times, prey size and species selection in Cancer novaezelandiae (Jacquinot, 1853) feeding on molluscan prey. Journal of Experimental Marine Biology and Ecology 140: 13-28.

Cuddington, K. \& A. Hastings, 2004. Invasive engineers. Ecological Modelling 178: 3-4.

Czerniejewski, P., A. Rybczyk \& W. Wawrzyniak, 2010. Diet of the Chinese mitten crab, Eriocheir sinensis H. Milne Edwards, 1853, and the potential effects of the crab on the aquatic community in the river Odra/Oder estuary (N.-W. Poland). Crustaceana 83: 195-205.

Daehler, C. \& D. Strong, 1997. Hybridization between introduced cordgrass (Spartina alterniflora; Poaceae) and native California cordgrass (S. foliosa) in San Francisco Bay, California, USA. American Journal of Botany 84: 607-611.

Dick, J. T. A., R. W. Elwood \& W. A. Montgomery, 1995. The behavioural basis of a species replacement: differential aggression and predation between the introduced Gammarus pulex and the native G. duebeni celticus (Amphipoda). Behavioural Ecology \& Sociobiology 37: 393-398.

Elner, R. W. \& R. N. Hughes, 1978. Energy maximization in the diet of the shore crab, Carcinus maenas. Journal of Animal Ecology 27: 103-116.

Erickson, A. A., I. C. Feller, V. J. Paul, L. M. Kwiatkowski \& W. Lee, 2008. Selection of an omnivorous diet by the mangrove tree crab Aratus pisonii in laboratory experiments. Journal of Sea Research 99: 59-69.

Freeman, A. S. \& J. E. Byers, 2006. Divergent induced responses to an invasive predator in marine mussel populations. Science 313: 831-833.

Galil, B. S., 2008. Alien species in the Mediterranean Sea which, when, where, why? Hydrobiologia 606: 105-116.

Geiger, W., P. Alcorlo, A. Baltanás \& C. Montes, 2005. Impact of an introduced Crustacean on the trophic webs of Mediterranean wetlands. Biological Invasions 7: 49-73.

Gherardi, F., F. Tarducci \& F. Micheli, 1989. Energy maximization and foraging strategies in Potamon fluviatile (Decapoda, Brachyura). Freshwater Biology 22: 233-245.

Gilbey, V., M. J. Attrill \& R. A. Coleman, 2008. Juvenile Chinese mitten crabs (Eriocheir sinensis) in the Thames estuary: distribution, movement and possible interactions with the native crab Carcinus maenas. Biological Invasions 10: 67-77.

Grason, E. W. \& B. G. Miner, 2012. Preference alters consumptive effects of predators: top-down effects of a native crab on a system of native and introduced prey. PLOS ONE 7: e51322.

Griffen, B. D. \& J. E. Byers, 2006. Partitioning mechanisms of predator interference in different habitats. Oecologia 146: 608-614.

Haddaway, N. R., R. H. Wilcox, R. E. A. Heptonstall, H. M. Griffiths, R. J. G. Mortimer, M. Christmas \& A. 
M. Dunn, 2012. Predatory functional response and prey choice identify predation differences between native/invasive and parasitised and unparasitised crayfish. PLoS ONE 7: e32229.

Herborg, L. M., S. P. Rushton, A. S. Clare \& M. G. Bentley, 2005. The invasion of the Chinese mitten crab (Eriocheir sinensis) in the United Kingdom and its comparison to continental Europe. Biological Invasions 7: 959-968.

Hudson, I. R. \& B. D. Wigham, 2003. In situ observations of predatory feeding behaviour of the galatheid squat lobster Munida sarsi using a remotely operated vehicle. Journal of the Marine Biological Association of the United Kingdom 83: 463-464.

Hughes, R. N., 1971. Ecological energetics of Nerita (Archeogastropoda, Neritacea) populations on Barbados, West Indies. Marine Biology 11: 12-22.

Hughes, R. N. \& R. Seed, 1981. Size selection of mussels by the blue crab Callinectes sapidus: energy maximizer or time minimizer? Marine Ecology Progress Series 6: 83-89.

Hymanson, Z., J. Wang \& T. Sasaki, 1999. Lessons from the home of the Chinese mitten crab. IEP Newsletter 12: 25-32.

Jackson, A. C. \& A. J. Underwood, 2007. Application of new techniques for the accurate analysis of choice of prey. Journal of Experimental Marine Biology and Ecology 341: $1-9$.

Karatayev, A. Y., L. E. Burlakova, D. K. Padilla, S. E. Mastitsky \& S. Olenin, 2009. Invaders are not a random selection of species. Biological Invasions 11: 2009-2019.

Kiesecker, J. M., A. R. Blaustein \& C. L. Miller, 2001. Potential mechanisms underlying the displacement of native red-legged frogs by introduced bullfrogs. Ecology 82: 1964-1970.

Laitano, M. V., N. E. Farías \& M. Cledón, 2013. Prey preference of the stone crab Platyxanthus crenulatus (Decapoda: Platyxanthidae) in laboratory conditions. Nauplius 21: $17-23$.

Landschoff, J., D. Lackschewitz, K. Kesy \& K. Reise, 2013. Globalization pressure and habitat change: Pacific rocky shore crabs invade armored shorelines in Atlantic Wadden Sea. Aquatic Invasions 8: 77-87.

Lien, L., 1978. The energy budget of the brown trout population of the Øvre Heimdalsvatn. Holarctic Ecology 1: 279-300.

Lilley, J. H., L. Corenius \& K. Söderhäll, 1997. RAPD evidence for the origin of crayfish plague outbreaks in Britain. Aquaculture 157: 181-185.

Lowe, S., M. Browne, S. Boudjelas \& M. De Poorter, 2000. 100 of the World's Worst Invasive Alien Species: A Selection from the Global Invasive Species Database. Published by The Invasive Species Specialist Group (ISSG). First published as special lift-out in Aliens 12, December 2000. Updated and reprinted version: November 2004.

McDonald, P. S., G. C. Jensen \& D. A. Armstrong, 2001. The competitive and predatory impacts of the nonindigenous crab Carcinus maenas (L.) on early benthic phase Dungeness crab Cancer magister Dana. Journal of Experimental Marine Biology and Ecology 258: 39-54.

Nakata, K. \& S. Goshima, 2006. Asymmetry in mutual predation between the endangered Japanese native crayfish Cambaroides japonicus and the North American invasive crayfish Pacifastacus leniusculus: a possible reason for species replacement. Journal of Crustacean Biology 26: 134-140.
Ranasinghe, J. A., T. K. Mikel, R. G. Verlarde, S. B. Weisberg, D. E. Montagne, D. B. Cadien \& A. Dalkey, 2005. The prevalence of non-indigenous species in southern California embayments and their effects on benthic macroinvertebrate communities. Biological Invasions 7: 679-686.

Rochette, R., S. P. Doyle \& T. C. Edgell, 2007. Interaction between an invasive decapod and a native gastropod: predator foraging tactics and prey architectural defences. Marine Ecology Progress Series 330: 179-188.

Rossong, M. A., P. J. Williams, M. Comeau, S. C. Mitchell \& J. Apaloo, 2006. Agonistic interactions between the invasive green crab, Carcinus maenas (Linnaeus) and juvenile American lobster, Homarus americanus (Milne Edwards). Journal of Experimental Marine Biology and Ecology 329: 281-288.

Rudnick, D. \& V. Resh, 2005. Stable isotopes, mesocosms and gut content analysis demonstrate trophic difference in two invasive decapod Crustacea. Freshwater Biology 50: 1323-1336.

Rumohr, H., T. Brey \& S. Ankar, 1987. A compilation of biometric conversion factors for benthic invertebrates of the Baltic Sea. Baltic Marine Biology Publication 9: 1-56.

Salo, P., E. Korpimäki, P. B. Banks, M. Nordström \& C. R. Dickman, 2007. Alien predators are more dangerous than native predators to prey populations. Proceedings of the Royal Society B: Biological Sciences 274: 1237-1243.

Sanders, N. J., N. J. Gotelli, N. E. Heller \& D. M. Gordon, 2003. Community disassembly by an invasive species. Proceedings of the National Academy of Sciences of United States of America 100: 2474-2477.

Schindler, D. E., B. M. Johnson, N. A. MacKay, N. Bouwes \& J. F. Kitchell, 1994. Crab: snail size-structured interactions and salt marsh predation gradients. Oecologia 97: 49-61.

Shigemiya, Y., 2003. Does the handedness of the pebble crab Eriphia smithii influence its attack on two dextral snail species? Journal of Zoology 260: 259-265.

Stehlik, L. L., 1993. Diets of the brachyuran crabs Cancer irroratus, $C$. borealis and Ovalipes ocellatus in the New York Bight. Journal of Crustacean Biology 13: 723-735.

Taplin, R. H., 2007. Experimental design and analysis to investigate predator preferences for prey. Journal of Experimental Marine Biology and Ecology 344: 116-122.

Walton, W. C., C. MacKinnon, L. F. Rodriquez, C. Proctor \& G. M. Ruiz, 2002. Effects of an invasive crab upon a marine fishery: green crab, Carcinus maenas, predation upon a venerid clam, Katelysia scalarina, in Tasmania (Australia). Journal of Experimental Marine Biology and Ecology 272: 171-189.

Webster, J. M., P. F. Clark \& D. Morritt, 2015. Laboratory based feeding behaviour of the Chinese mitten crab, Eriocheir sinensis, (Crustacea: Decapoda, Brachyura, Varunidae): fish egg consumption. Biological Invasions 10: 313-326.

Weissburg, M., 1993. Sex and the single forager: genderspecific energy maximization strategies in fiddler crabs. Ecology 74: 279-291.

Wiles, G. J., J. Bart, R. E. Beck Jr \& C. F. Aguon, 2003. Impacts of the brown tree snake: patterns of decline and specie persistence in Guam's avifauna. Conservation Biology 17: 1350-1360.

Williams, M. J., 1982. Natural food and feeding in the commercial sand crab Portunus pelagicus Linnaeus, 1766 
(Crustacea: Decapoda: Portunidae) in Moreton Bay, Queensland. Journal of Experimental Marine Biology and Ecology 59: 165-176.
Zipser, E. \& G. J. Vermeij, 1978. Crushing behaviour of tropical and temperate crabs. Journal of Experimental Marine Biology and Ecology 31: 155-172. 